습성 나이관련황반변성에서 5 회 주사 시 시력이 0.1 이하였던 환자들의 1년 추적 결과

\title{
Long-Term Visual Outcomes in Patients with Neovascular AMD Who Exhibited Visual Acuity of 0.1 or Worse at 5 th Injection
}

\author{
태기선 ${ }^{1}$, 김종우 ${ }^{2}$, 김철구 $^{2}$, 이동원 ${ }^{2}$, 김재휘 ${ }^{2}$ \\ Kee Sun Tae', Jong Woo Kim², Chul Gu Kim², Dong Won Lee², Jae Hui Kim² \\ ${ }^{1}$ 태안과, ${ }^{2}$ 건양대학교 의과대학 김안과병원 안과 \\ ${ }^{1}$ Dr. Tae Eye Clinic, Seoul, Korea \\ ${ }^{2}$ Department of Ophthalmology, Kim's Eye Hospital, Konyang University College of Medicine, Seoul, Korea
}

Purpose: To evaluate one-year follow-up outcomes of patients with neovascular age-related macular degeneration (AMD) who exhibited best-corrected visual acuity (BCVA) of 0.1 or worse at the 5th anti-vascular endothelial growth factor (VEGF) injection. The factors associated with visual prognosis were additionally investigated.

Methods: This retrospective study included 21 eyes (21 patients) diagnosed with neovascular AMD exhibiting BCVA of 0.1 or worse (0.1:13 eyes, worse than 0.1:8 eyes) at the 5th anti-VEGF (VEGF) injection. The timing of the 5 th injection was identified. In addition, factors associated with 0.1 or better BCVA at 12 months after the 5th injection were investigated

Results: The timing of the 5th injection was a mean $9.1 \pm 3.2$ months after diagnosis. The mean logarithm of minimal angle of resolution BCVA at the 5th injection and at 12 months after was $1.14 \pm 0.20$ and $1.21 \pm 0.40$, respectively. At 12 months after the 5th injection, 8 eyes (38.1\%) and 3 eyes (14.3\%) exhibited BCVA of 0.1 and 0.2 , respectively. The BCVA at the 5th injection was significantly associated with that measured at 12 months after $(p=0.008)$.

Conclusions: In eyes exhibiting BCVA of 0.1 or worse at the 5th injection, visual acuity was not significantly changed during 12-months of treatment, and the BCVA at the 5th injection was predictive of the 12-month visual outcome. Visual improvement was noted in some eyes, suggesting the need for continuous treatment for these eyes.

Keywords: Aflibercept; Age-related macular degeneration; Anti-vascular endothelial growth factor; Choroidal neovascularization; Ranibizumab

\section{Address reprint requests to Jae Hui Kim, MD}

Department of Ophthalmology, Kim's Eye Hospital, \#136 Yeongsin-ro, Yeongdeungpo-gu, Seoul 07301, Korea Tel: 82-2-2639-7664, Fax: 82-2-2639-7824

E-mail: kjh7997@daum.net
Received: 2018. 5.21

Revised: 2018. 7. 13

Accepted: 2018. 7. 16

*This work was supported by Kim's Eye Hospital Research Center. 
서론

습성 나이관련황반변성은 실명의 주된 원인 중 하나이다[1]. 습 성 나이관련황반변성의 자연 경과는 매우 좋지 않아 심각한 시 력 저하가 발생할 수 있으며[2], 이와 동반하여 삶의 질 또한 저 하되는 것으로 알려져 있다[3]. 유리체강내 항혈관내피성장인 자 주사는 습성 나이관련황반변성의 치료에 효과적인 방법으 로[4,5] 현재 이 질환에 대한 표준 치료로 널리 이용되고 있다.

라니비주맙(Lucentis ${ }^{\mathrm{TM}}$; Genentech, San Francisco, CA, USA) 과 애플리버셉트(Eylea ${ }^{\mathrm{TM}}$; Regeneron, Tarrytown, NY, USA)는 국내 식품의학안전처의 승인을 받아 습성 나이관련황반변성의 치료에 이용되고 있는 약제로 환자의 시력을 유지시키거나 호 전시키는 데에 뛰어난 효과를 보였다[4,5]. 국내에서 라니비주맙 혹은 애플리버셉트 치료 시 건강보험의 지원을 받을 수 있는 제 도적 뒷받침이 있어 왔으나 2017년 12월 1일 이전에는 건강보험 지원이 가능한 횟수에 제한을 두었다. 2017년 12월 1일부터 보 험 제도의 변경에 따라 횟수 제한은 없어졌으나 5 회 주사부터는 교정시력이 0.1 이하인 경우 적절한 사유 없이는 보험급여를 적 용받기 어렵도록 규정이 변경되었다. 따라서 국내 환자를 치료 하는 경우 5 회 주사 시 0.1 이하로 시력이 측정된 환자들의 예후 에 대한 연구는 중요한 의미를 가질 수 있을 것으로 판단된다.

현재까지 습성 나이관련황반변성의 치료 결과를 분석한 수많 은 연구 결과가 발표되었으나 5 회 주사 시 시력에 중점을 맞추 어 분석한 연구는 없었다. 이에 본 연구에서는 5 회 주사 시 시력 이 0.1 이하로 측정된 환자들의 1 년 추적 결과를 알아보고, 시 력 예후와 관련된 인자를 분석하고자 한다.

\section{대상과 방법}

본 연구는 단일 기관에서 시행된 후향적 연구로 헬싱키선언에 입각하여 시행되었으며, Institutional Review Board (IRB) 승인 을 획득하였다(Kim's Eye Hospital-IRB). 2014년 5월부터 2015년 2 월까지 습성 나이관련황반변성으로 진단 후 최초 치료로 1 개 월 간격 3회의 라니비주맙 혹은 애플리버셉트 주사를 시행받았 으며, 5회 주사 시 최대교정시력이 0.1 (decimal) 이하로 측정된 안을 대상으로 후향적 의무기록 분석을 시행하였다. 다음과 같 은 경우 연구에서 제외하였다. 1) 5 회 주사 후 12 개월 미만의 추 적관찰 기간, 2) 재발 여부과 관련 없이 지속적으로 주사하는 proactive 치료를 시행받은 경우, 3) 첫 3회 주사 후 기존 약제에 효과가 제한적인 것으로 판정되어 바로 교체 투여를 시행한 경 우, 4) 심한 매체 혼탁, 5) 이전에 유리체망막수술을 받은 병력이 있는 경우, 6) 5 회 주사 후 12 개월 이내에 백내장수술이나 유리 체망막수술을 시행받은 경우, 7) 증식당뇨망막병증, 망막혈관폐 쇄, 8) 황반원공이나 망막전막 등 황반미세구조와 시기능에 영
향을 미칠 수 있는 기타 유리체망막 질환이 동반된 경우. 양안 이 진단된 경우 증상이 먼저 나타난 안을 연구에 포함하였다.

진단 시 환자의 최대교정시력을 측정하였으며, 세극등을 이용 한 안저검사 및 빛간섭단층촬영(SLO-OCT ${ }^{\mathrm{TM}}$ : OTI Ophthalmic Technologies Inc, Toronto, Canada; Spectralis ${ }^{\mathrm{TM}}$ : Heidelberg Engineering, Heidelberg, Germany; RS 3000' ${ }^{\mathrm{TM}}$ : Nidek Co., Ltd., Tokyo, Japan) 및 형광안저혈관조영술을 시행하였다.

모든 환자는 진단 후 1 개월 간격으로 3 회의 라니비주맙 $(0.5$ $\mathrm{mg} / 0.05 \mathrm{~mL})$ 혹은 애플리버셉트 $(2.0 \mathrm{mg} / 0.05 \mathrm{~mL})$ 주사를 시 행받았다. 유리체내 주사는 외래 수술실에서 시행되었다. 시술 전 0.5\% proparacaine (Alcaine®; Alcon, Fort Worth, TX, USA) 을 점안한 뒤 $1.25 \%$ povidone iodine을 시술할 눈에 점안하고 속눈썹을 포함하여 눈 주위를 닦았다. 개검기를 끼우고 $1.25 \%$ povidone iodine을 한 번 더 점안한 뒤 각막 윤부에서 $3.0 \mathrm{~mm}$ 혹은 $3.5 \mathrm{~mm}$ 하측 사분면 혹은 상측 사분면에 30 게이지 일회 용 바늘을 이용하여 주사를 시행하였다.

첫 3회 주사 이후 1-2개월 간격으로 경과관찰을 시행하였으 며, 장기간 재발이 없던 경우 의사의 판단에 따라 3-4개월까지 경과관찰 간격을 연장하였다. 모든 환자들은 추적관찰 시 세극 등을 이용한 안저검사 및 빛간섭단층촬영을 시행하였다. 빛간 섭단층촬영에서 중심와를 침범하거나 위협하는 망막하액/망막 내액이 발생한 경우 혹은 안저검사에서 망막/망막하 출혈이 발 생한 경우를 질환의 활동성이 재발한 것으로 판단하고 추가 주 사를 시행하였다. 국내 보험 기준에 따라 첫 3 회 주사 이후 주 사 간격은 라니비주맙은 최소 4주, 애플리버셉트는 최소 8주 이 상으로 유지하였다.

진단 당시, 3 개월, 5 회 주사 시 및 5 회 주사 후 12 개월에 각각 측정된 최대교정시력을 확인하였으며, 5 회 주사의 시기를 추가 적으로 확인하였다. 5 회 주사 12 개월 후 0.1 혹은 0.2 의 시력을 예측할 수 있는 인자를 확인하기 위하여 각 인자들을 아래와 같이 2개 군으로 구분하였다; 환자의 나이: 71세 이하 vs. 72 세 이상, 성별: 남성 vs. 여성, 진단 시 병변의 크기: $6.20 \mathrm{~mm}^{2}$ 미만 vs. $6.20 \mathrm{~mm}^{2}$ 이상, 5 회 주사 시점: 진단 후 9 개월 미만 vs. 진단 후 9개월 혹은 그 이후, 진단 시의 시력: 0.1 이상 vs. 0.1 미만, 3 개 월 시력: 0.2 이상 vs. 0.2 미만, 5 회 주사 시의 시력: 0.1 vs. 0.1 미만. 5 회 주사 12 개월 후의 시력이 0.2 이상인 경우의 비율을 양 군 간에 서로 비교하였다.

5 회 주사 12 개월 후 시력의 경우 환자가 정확히 12 개월 시점 에 방문하지 않았을 때에는 그 시점으로부터 가장 가까운 시 점의 값으로 대체하였다. 최대교정시력은 통계분석을 위하여 logarithm of minimal angle of resolution (logMAR) 값으로 변 환하였다. 병변의 크기는 형광안저혈관조영술 이미지를 이용하 여 측정하였으며, 형광 누출과 염색 및 출혈 범위 전체를 포함 하여 측정하였다. 통계 분석에는 SPSS 프로그램(SPSS ver. 12.0 for Windows; SPSS Inc., Chicago, IL, USA)을 이용하였다. 서 
로 다른 양 군 간의 비교는 Fisher's exact test를 이용하였으며, 0.05 미만의 $p$ 값을 통계적으로 유의한 값으로 정의하였다.

\section{결과}

전체 21안(21명)을 대상으로 연구를 시행하였다(Table 1). 남성 12 명, 여성 9명이었으며, 평균 연령은 $72.9 \pm 6.9$ 세였다. 5 회 주 사가 시행된 시기는 진단 후 평균 $9.1 \pm 3.2$ 개월이었으며, 진단 시부터 5 회 주사 후 12 개월까지 시행된 평균 주사 횟수는 7.2 \pm 1.0 회였다.

최초 진단 시, 3 개월, 5 회 주사 시 및 5 회 주사 후 12 개월 시점 에 측정한 평균 $\log \mathrm{MAR}$ 최대교정시력은 $1.20 \pm 0.31,0.96 \pm$ $0.34,1.14 \pm 0.20$ 및 $1.21 \pm 0.40$ 이었다(Fig. 1). 5 회 주사 시와 비교하였을 때, 주사 후 12 개월에 $\log$ MAR 시력 0.3 이상의 호 전을 보인 경우는 3안(14.3\%), 0.3 이상의 악화를 보인 경우는 6 안 (28.6\%)이었으며, 나머지 12안(57.1\%)은 시력에 큰 변동이 없었 다. 5 회 주사 시 시력이 0.1 이었던 13 안 중 10 안(76.9\%)에서 시 력이 유지되거나 호전되었으며, 5 회 주사 시 시력이 0.1미만이었 던 8 안 중 시력이 유지되거나 호전된 경우는 5안(62.5\%)이었다.

진단 당시 최대교정시력이 0.1 이상 및 0.1 미만으로 측정된 안 은 각각 11 안(52.4\%) 및 10 안(47.6\%)이었으며, 3개월에는 각각 17안 (80.9\%) 및 4안(19.0\%), 5회 주사 시에는 각각 13안(61.9\%) 및 8

Table 1. Characteristics of 21 patients (21 eyes) with neovascular age-related macular degeneration in whom the BCVA was 0.1 (decimal) or worse when the 5th anti-vascular endothelial growth factor injection was performed

\begin{tabular}{lc}
\hline Characteristic & Value \\
\hline Age (years) & $72.9 \pm 6.7$ \\
Sex & $12(57.1)$ \\
$\quad$ Men & $9(42.9)$ \\
$\quad$ Women & $10(47.6)$ \\
Hypertension & $4(19.0)$ \\
Diabetes mellitus & $6.2 \pm 2.4$ \\
Lesion size (mm²) & $1.20 \pm 0.31$ \\
Baseline BCVA (logMAR) & $9.1 \pm 3.2$ \\
Timing of 5th injection (months) & \\
BCVA at 5th injection (decimal) & $13(61.9)$ \\
0.1 & $8(38.1)$ \\
\hline
\end{tabular}

Values are presented as mean \pm standard deviation or number (\%). $\mathrm{BCVA}=$ best-corrected visual acuity; logMAR = logarithm of minimal angle of resolution.
안(38.1\%), 5 회 주사 12 개월 이후에는 각각 11 안 $(52.4 \%)$ 및 10 안 (47.6\%)이었다(Fig. 2). 5 회 주사 후 12개월에 시력이 0.2로 호전 된 안은 3안(14.3\%)이었다(Fig. 3). 이들 3안은 모두 3개월에 0.2 이상, 5 회 주사 시 0.1 의 시력을 보인 경우였다.

5 회 주사 시 시력이 0.1 이었던 13 안 중 10 안(76.9\%)에서 12 개 월 시력이 0.1 혹은 0.2 였던 반면 5 회 주사 시 시력이 0.1 미만이 었던 8안 중 1안(12.5\%)에서만 12개월 시력 0.1 혹은 0.2 로 측정 되어 5 회 주사 시 시력이 0.1 인 경우, 0.1 미만인 경우에 비하여 주사 12 개월 후 시력이 0.1 혹은 0.2 로 측정된 비율이 유의하게 더 높은 것으로 나타났다 $(p=0.008$, Table 2). 다른 인자들인 나

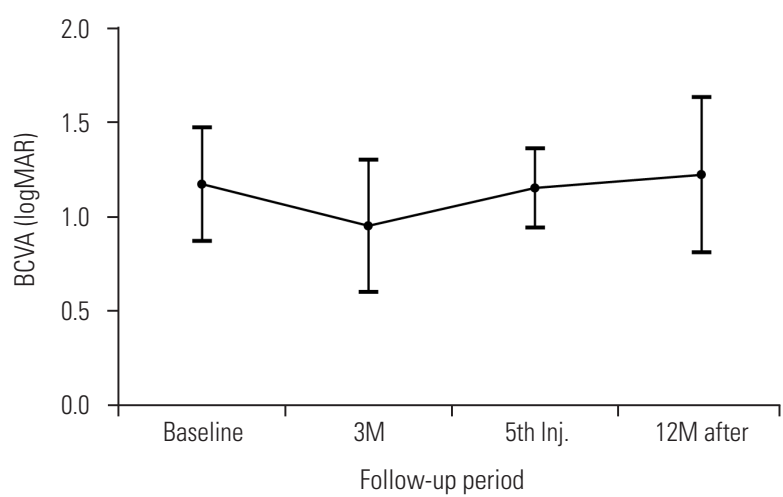

Figure 1. Changes in logarithm of minimal angle of resolution (logMAR) best-corrected visual acuity (BCVA) in all 21 included eyes. $3 \mathrm{M}$ $=3$ months after diagnosis (1 month after 3 loading injections); 5th $\operatorname{Inj} .=$ when the 5 th injection was performed; $12 \mathrm{M}$ after $=12$ months after the 5 th injection.

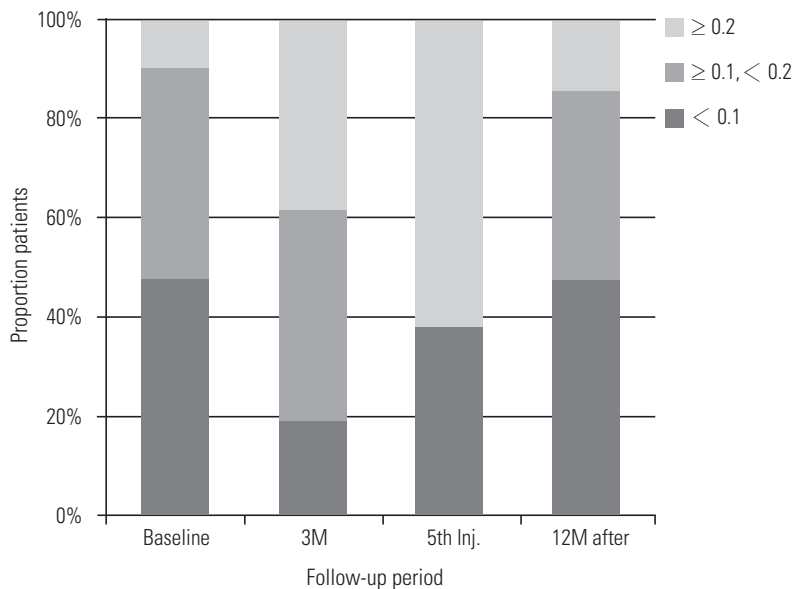

Figure 2. Changes in the proportion of eyes exhibited best-corrected visual acuity (BCVA) 0.2 (decimal) or better $(\geq 0.2), 0.1$ or better but worse than $0.2(\geq 0.1,<0.2)$, and worse than $0.1(<0.1) .3 \mathrm{M}=3$ months after diagnosis ( 1 month after 3 loading injections); 5 th $\operatorname{lnj} .=$ When the 5 th injection was performed; $12 \mathrm{M}$ after $=12$ months after the 5 th injection. 

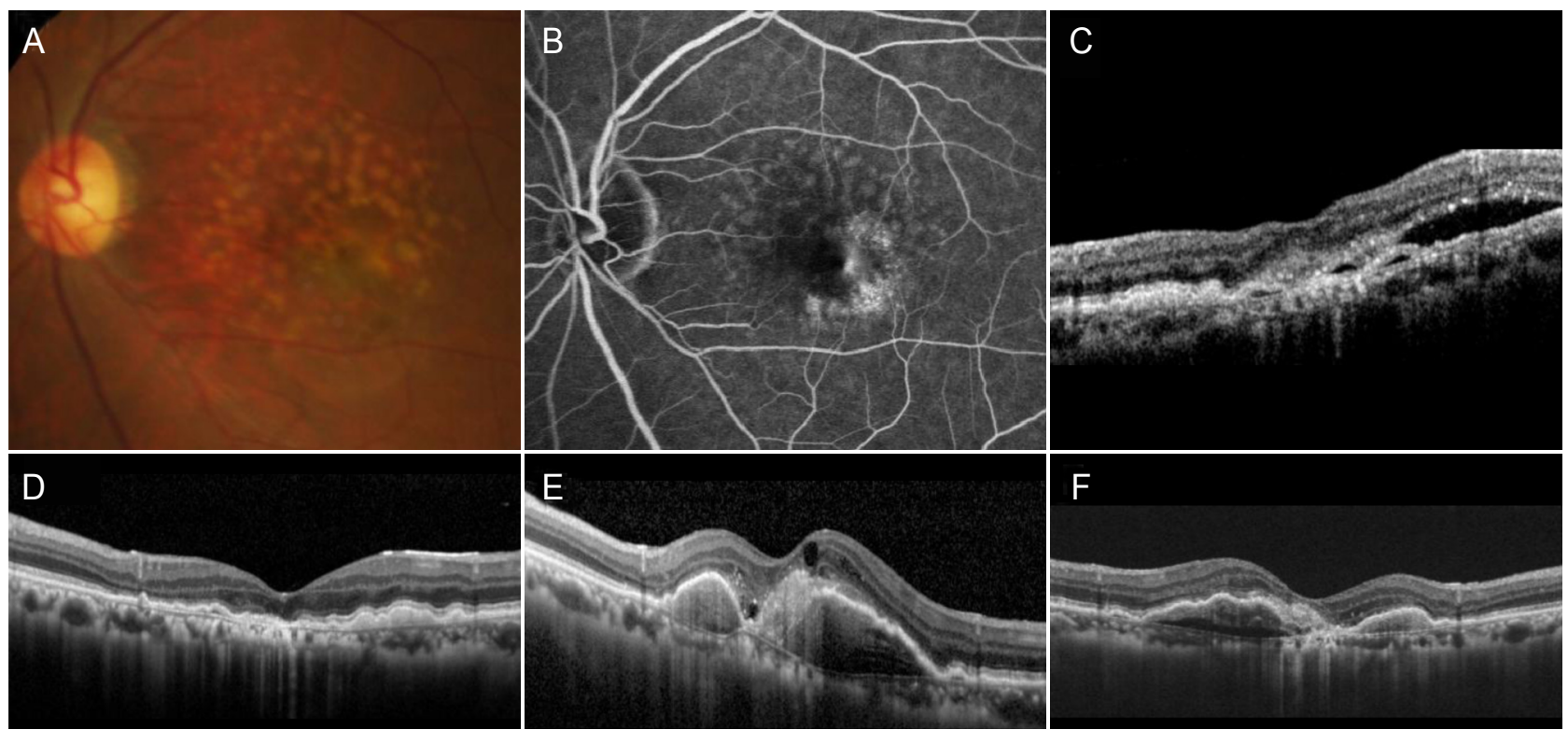

Figure 3. A representative case showing long-term improvement of visual acuity after 5th anti-vascular endothelial growth factor injection. At diagnosis (A-C), the best-corrected visual acuity (BCVA) was measured as 0.1 (decimal). The BCVA improved to 0.3 after 3 monthly anti-vascular endothelial growth factor injections (D). After 13 months BCVA had deteriorated to 0.1 with recurrence of fluid (E) and 5 th injection was performed. Twelve months after the 5th injection (F), the BCVA had improved to 0.2 (A, fundus photography; B, fluorescein angiography; C-F, optical coherence tomography).

Table 2. Factors associated with best-corrected visual acuity 0.1 (decimal) or better at 12 months after 5th injection

\begin{tabular}{|c|c|c|c|}
\hline \multirow{2}{*}{ Factor } & \multicolumn{2}{|c|}{ BCVA at 12 months after 5th injection } & \multirow{2}{*}{$p$-value* } \\
\hline & 0.1 or better & Worse than 0.1 & \\
\hline Age & & & 0.395 \\
\hline 71 years or younger & $7(63.6)$ & $4(36.4)$ & \\
\hline 72 years or older & $4(40.0)$ & $6(60.0)$ & \\
\hline Sex & & & 0.198 \\
\hline Male & $8(66.7)$ & $4(33.3)$ & \\
\hline Female & $3(33.3)$ & $6(66.7)$ & \\
\hline Lesion size & & & 0.670 \\
\hline Smaller than $6.20 \mathrm{~mm}^{2}$ & $4(44.4)$ & $5(55.6)$ & \\
\hline $6.20 \mathrm{~mm}^{2}$ or larger & $7(58.3)$ & $5(41.7)$ & \\
\hline Timing of 5th injection & & & 0.086 \\
\hline Before 9 months after diagnosis & $3(30.0)$ & $7(70.0)$ & \\
\hline 9 months or after & $8(72.7)$ & $3(27.3)$ & \\
\hline Baseline BCVA & & & 0.395 \\
\hline 0.1 or better & $7(63.6)$ & $4(36.4)$ & \\
\hline Worse than 0.1 & $4(40.0)$ & $6(60.0)$ & \\
\hline BCVA at 5th injection & & & 0.008 \\
\hline 0.1 & $10(76.9)$ & $3(23.1)$ & \\
\hline Worse than 0.1 & $1(12.5)$ & $7(87.5)$ & \\
\hline
\end{tabular}

Values are presented as number (\%).

$\mathrm{BCVA}=$ best-corrected visual acuity.

*Statistical analysis performed using Fisher's exact test. 
이 $(p=0.395)$, 성별 $(p=0.198)$, 병변의 크기 $(p=0.670), 5$ 회 주사 시점 $(p=0.086)$ 및 진단 당시 시력 $(p=0.395)$ 은 5 회 주사 12 개월 후의 시력과 유의한 연관성이 나타나지 않았다.

\section{고찰}

습성 나이관련황반변성에서 유리체강내 항혈관내피성장인자 주사의 효과를 평가한 초기 임상시험에서는 비교적 많은 횟수 의 주사를 시행하였는데, 라니비주맙의 경우 매달 지속적으로 주사하는 방법을 이용하였고[4], 애플리버셉트의 경우 첫 3회 매달 주사 후 2개월 간격으로 지속 주사하는 방법을 이용하였 다[5]. 그러나 이들 약제가 상당히 고가라는 점을 고려하였을 때, 이러한 방식의 치료를 지속하는 데에는 경제적 부담이 커 지는 문제점이 있었으며[6], 약제의 뛰어난 효과에도 불구하고 치료비 부담의 증가는 사회경제적 문제로 대두되었다[7]. 현재 는 보다 효율적인 치료를 위하여 도입된 as-needed 방식이나 treat-and-extend 방식이 널리 이용되고 있으나 치료 비용에 관 련된 문제는 여전히 남아 있는 상태이다[8].

습성 나이관련황반변성은 비가역적인 시력 손상을 유발할 수 있는 질환으로 항혈관내피성장인자 치료를 시행하는 경우 에도 일부 환자에서는 지속적인 시력의 저하가 나타나게 된 다[9]. 항혈관내피성장인자 치료의 경제적 부담을 고려하였을 때, 시력이 이미 많이 손상된 환자를 대상으로 한 지속적인 주 사 치료는 비용-효과 측면에서 바람직하지 않을 수 있다는 우 려가 제기되었다[10]. 따라서 반대쪽 눈이 실명한 last eye 환자 와 같이 특수한 경우를 제외한다면 이러한 환자들에 대한 치 료 방침을 결정할 때에는 향후 시력의 유지 혹은 호전 가능성 을 어느 정도 예측해 보고, 추가 주사가 환자에게 얼마나 도움 이 될 것인가를 충분히 생각해 보아야 할 것이다.

일반적으로 습성 나이관련황반변성의 시력 예후를 예측하는 연구에서는 진단 당시를 기준으로 한 시력, 질환 및 환자의 특 성들 중에서 치료 후 시력을 예측할 수 있는 인자가 있는지를 분석하였다[11-13]. 기존 연구 결과에 따르면 나이[12,13], 병변 의 크기[12,13], 진단 당시의 시력[12,13], 신생혈관의 종류[11], 혈전용해제의 사용 여부[11] 등이 장기 시력 예후와 연관된 것 으로 나타났다. 진단 당시 시력이 0.1 혹은 그 이하로 좋지 않 았던 안을 대상으로 항혈관내피성장인자 치료 결과를 분석한 기존 연구들의 경우 43-70\%에서 시력이 유지되거나 호전되었 는데, 이와 같은 연구 결과는 초기 시력이 좋지 않은 경우에도 적극적인 치료가 도움이 될 수 있다는 점을 시사한다[14,15]. 그 러나 진단 당시 시력을 기준으로 한 상기 연구 결과를 본 연구 에서와 같이 치료 도중에 측정된 시력에 직접적으로 적용하기 는 어려울 것이다. 습성 나이관련황반변성에 대한 치료를 언 제 중단해야 하는가?'에 대해서는 아직 정해진 기준이 없으며,
치료자의 경험과 지식에 기초하여 개별적으로 판단하는 경우 가 많다. Elshout et al. [10]은 습성 나이관련황반변성에서 시 력과 삶의 질 사이의 연관관계에 대하여 연구하였는데, 0.05 미만 시력의 경우 시력의 변화가 삶의 질에 유의한 영향을 미 치지 않았다. 이와 같은 결과를 바탕으로 Elshout et al. [10]은 0.05 미만 시력이 회복 불가능한 것으로 판단되는 경우 치료 중단을 고려할 수 있다고 제안하였다. 그러나 치료 중단에 대 한 판단은 각 환자의 상태에 따라 다를 수 있음을 추가적으로 강조하였는데[10], 이는 습성 나이관련황반변성에서 치료 중단 에 대한 기준을 명확하게 정하기 어렵다는 점을 보여주고 있다.

본 연구에서는 '5회 주사 시 0.1 의 시력'을 중요하게 고려하는 현행 국내 보험 제도의 특성을 반영하여 습성 나이관련황반변 성에 대한 5 회 주사 시 시력이 0.1 이하였던 환자들의 12 개월 추적 결과에 초점을 맞춘 분석을 시행하였다. 기존 연구들에 서 장기 시력 예후와 밀접하게 연관된 것으로 나타난 진단 당 시의 각종 특성들의 경우[11-13] 본 연구에서 5회 주사 12개월 후에 측정된 시력과는 유의한 관련성이 나타나지 않았다. 그러 나 5 회 주사 시의 시력은 이후 12 개월에 측정된 시력을 예측할 수 있는 인자로 나타났는데, 5 회 주사 시 시력이 0.1 로 측정된 경우의 대부분에서 주사 후 12 개월 시력이 0.1 혹은 0.2 로 측정 되었으나, 시력이 0.1 미만이었던 경우에는 0.1 혹은 0.2 시력으 로 회복될 가능성이 낮은 것으로 나타났다. 특히 시력이 0.1 이 었던 안들의 $76.9 \%$ 에서 시력이 유지되거나 호전되었는데, 이와 같은 결과는 추가적인 치료가 0.1 시력의 환자들에게 도움이 될 수 있다는 점을 시사하는 소견으로 생각된다.

본 연구에서는 $14.3 \%$ 에서 $\log \mathrm{MAR}$ 시력 0.3 이상의 호전을 보였는데, 이는 일반적으로 “뚜렷한 시력 호전'의 기준으로 자 주 이용되는 시력표 3줄 이상의 시력 호전'에 해당하는 변화이 다. 기존의 임상시험 결과에 따르면 습성 나이관련황반변성에 서 항혈관내피성장인자를 매달 주사하는 적극적인 방법을 시 행하였을 때, $33.8 \%$ 에서 12 개월 시력이 시력표 3줄 이상 호전 된 것으로 나타났다[4]. 일반적으로 실제 진료 환경에서의 치 료 결과는 임상시험에 비하여 좋지 않다는 점을 고려하였을 때[16], 본 연구에서 나타난 $14.3 \%$ 라는 비율은 의미 있는 수치 로 생각되며, 추가 치료가 이들 환자에서 뚜렷한 효과가 있었 음을 보여준다.

다만 $\log \mathrm{MAR}$ 시력이 0.3 이상 호전된 3안은 모두 첫 3회 주 사 후 시력이 0.2 이상으로 측정되었으며, 5 회 주사 시 0.1 의 시 력을 보인 경우였다. 이와 같은 결과를 고려해 보면, 첫 3회 주 사 후에도 시력이 0.2 이상으로 회복되지 못하였거나 5 회 주사 시 시력이 0.1 미만으로 측정된 경우에는 5 회 주사 후 장기적으 로 시력 호전의 가능성이 낮을 것으로 추측해 볼 수 있다. 그러 나 본 연구는 소수의 안을 대상으로 시행되었으므로, 이와 같 은 부분에 대해서는 다수의 안을 대상으로 한 추가 연구를 통 하여 다시 한 번 확인해야 할 것으로 생각된다. 
본 연구에는 다음과 같은 제한점들이 있다. 우선 본 연구는 후향적 연구로 소수의 안을 대상으로 결과를 분석하였다. 진단 후 1 개월 간격 3 회 항혈관내피성장인자 주사를 시행받은 안만 을 대상으로 하였기에, 본 연구의 결과는 1 회 혹은 2 회 주사 후 경과관찰한 경우에는 적용하기 어려울 것이다. 또한 본 연구에 서는 as-needed 치료에 준한 방법을 이용하였는데, as-needed 치료 시 권장되는 매달 경과관찰하는 방법[17]을 엄격하게 적용 하지 못하였으며, 치료자의 판단에 따라 경과관찰 사이의 기간 을 4개월까지 연장하였다. 따라서 일부 환자들의 경우 재발하 였을 때, 적절한 조기 치료가 이루어지지 못하여 시력 결과에 영향을 미쳤을 가능성이 있다. 마지막으로 본 연구의 결과는 재발 여부와 상관 없이 지속적으로 주사하는 proactive 방식으 로 치료한 환자들에게는 적용할 수 없을 것이다.

요약하면, 본 연구에서는 5회 주사 시 시력이 0.1 이하였던 안의 실제 임상에서 12 개월 추적 시력 결과와 예후인자에 대 하여 분석하였는데, 대부분의 안에서 5 회 주사 후 12 개월 동안 시력이 유지되거나 호전되는 결과를 보였으며, 특히 시력이 0.1이 었던 경우 이와 같은 경향이 보다 뚜렷하게 나타났다. 5 회 주사 시 시력은 주사 후 12 개월의 시력을 예측할 수 있는 인자로 나 타났다. 12 개월 후의 시력이 0.2 로 호전된 안의 경우, 모두 진 단 후 3 개월에 측정된 시력이 0.2 이상이면서 5 회 주사 시 시력 이 0.1 미만으로 악화되지 않았던 경우였다. 본 연구는 실제 진 료 환경에서 습성 나이관련황반변성을 치료할 때, 환자의 시력 예후를 예측하는 데에 유용한 정보를 제공해 줄 수 있을 것이 다. 그러나 본 연구에는 여러 제한점들이 있으며, 연구에 포함 된 환자들은 국내 보험 급여 기준에 따라 치료를 시행받았다. 향후 보다 많은 안을 대상으로 한 잘 통제된 추가 연구를 통하 여 ‘5회 주사 시 교정시력 0.1 이하’라는 현행 보험 기준의 효율 성에 대한 평가가 필요할 것이다.

\section{References}

1. Flaxman SR, Bourne RRA, Resnikoff S, et al. Global causes of blindness and distance vision impairment 1990-2020: a systematic review and meta-analysis. Lancet Glob Health 2017;5:e122134.

2. Wong TY, Chakravarthy U, Klein $\mathrm{R}$, et al. The natural history and prognosis of neovascular age-related macular degeneration: a systematic review of the literature and meta-analysis. Ophthalmology 2008;115:116-26.

3. Elshout M, Webers CA, van der Reis MI, et al. Tracing the natural course of visual acuity and quality of life in neovascular age-related macular degeneration: a systematic review and quality of life study. BMC Ophthalmol 2017;17:120.
4. Rosenfeld PJ, Brown DM, Heier JS, et al. Ranibizumab for neovascular age-related macular degeneration. N Engl J Med 2006;355:1419-31.

5. Heier JS, Brown DM, Chong V, et al. Intravitreal aflibercept (VEGF trap-eye) in wet age-related macular degeneration. Ophthalmology 2012;119:2537-48.

6. Smiddy WE. Economic implications of current age-related macular degeneration treatments. Ophthalmology 2009;116:481-7.

7. Day S, Acquah K, Lee PP, et al. Medicare costs for neovascular age-related macular degeneration, 1994-2007. Am J Ophthalmol 2011;152:1014-20.

8. Haller JA. Current anti-vascular endothelial growth factor dosing regimens: benefits and burden. Ophthalmology 2013;120(5 Suppl):S3-7.

9. Rofagha S, Bhisitkul RB, Boyer DS, et al. Seven-year outcomes in ranibizumab-treated patients in ANCHOR, MARINA, and HORIZON: a multicenter cohort study (SEVEN-UP). Ophthalmology 2013;120:2292-9.

10. Elshout $M$, van der Reis Ml, de Jong-Hesse $Y$, et al. Distinguishing between better and worse visual acuity by studying the correlation with quality of life in neovascular age-related macular degeneration. Ophthalmology 2016;123:2408-12.

11. Chae B, Jung JJ, Mrejen S, et al. Baseline predictors for good versus poor visual outcomes in the treatment of neovascular age-related macular degeneration with intravitreal anti-VEGF therapy. Invest Ophthalmol Vis Sci 2015;56:5040-7.

12. Lanzetta P, Cruess AF, Cohen SY, et al. Predictors of visual outcomes in patients with neovascular age-related macular degeneration treated with anti-vascular endothelial growth factor therapy: post hoc analysis of the VIEW studies. Acta Ophthalmol 2018 Apr 16. doi: 10.1111/aos.13751. [Epub ahead of print]

13. Regillo CD, Busbee BG, Ho AC, et al. Baseline predictors of 12-month treatment response to ranibizumab in patients with wet age-related macular degeneration. Am J Ophthalmol 2015;160:1014-23.e2.

14. Galbinur T, Averbukh E, Banin E, et al. Intravitreal bevacizumab therapy for neovascular age-related macular degeneration associated with poor initial visual acuity. Br J Ophthalmol 2009:93:1351-2.

15. Ehrlich R, Weinberger D, Priel E, Axer-Siegel R. Outcome of bevacizumab (Avastin) injection in patients with age-related macular degeneration and low visual acuity. Retina 2008;28:1302-7.

16. Holz FG, Tadayoni R, Beatty S, et al. Multi-country real-life experience of anti-vascular endothelial growth factor therapy for wet age-related macular degeneration. Br J Ophthalmol 
2015:99:220-6

17. Fung $A E$, Lalwani GA, Rosenfeld PJ, et al. An optical coherence tomography-guided, variable dosing regimen with intravitreal ranibizumab (Lucentis) for neovascular age-related macular degeneration. Am J Ophthalmol 2007;143:566-83.

\section{국문초록}

\section{습성 나이관련황반변성에서 5회 주사 시 시력이 0.1 이하였던 환자들의 1년 추적 결과}

목적: 습성 나이관련황반변성에서 5 회 주사 시 0.1 이하의 시력이었던 환자들의 1년 추적 결과를 알아보고 시력 결과와 관련된 인자를 분석하고자 한다.

대상과 방법: 습성 나이관련황반변성으로 진단 후 최초 치료로 1 개월 간격 3 회의 항혈관내피성장인자 주사를 시행받았으며, 5 회째 주 사 시 시력이 0.1 이하였던 21안(0.1: 13안, 0.1 미만: 8안)을 대상으로 후향적 의무기록 분석을 시행하였다. 5 회 주사의 시기를 확인 하였으며, 5 회 주사 12 개월 후 시력 0.1 이상을 예측할 수 있는 인자를 추가로 분석하였다.

결과: 5 회 주사가 시행된 시기는 진단 후 평균 $9.1 \pm 3.2$ 개월이었다. 5 회 주사 및 주사 후 12 개월 시점에 측정한 평균 logarithm of minimal angle of resolution 최대교정시력은 $1.14 \pm 0.20$ 및 $1.21 \pm 0.40$ 이었다. 5 회 주사 후 12 개월 시력이 0.1 로 측정된 경 우는 8안(38.1\%)이었으며, 3안(14.3\%)의 경우 0.2의 시력을 보였다. 5 회 주사 시 측정된 시력은 주사 후 12 개월의 시력과 유의한 연 관성이 있었다 $(p=0.008)$.

결론: 5 회 주사 시 시력이 0.1 이하였던 눈에 대한 1년 치료 결과, 시력에 유의한 차이는 없었으며, 5 회 주사 시 시력은 1년 후 시력을 예측할 수 있는 지표였다. 일부에서 시력 호전이 있어 선별적으로 지속적인 치료가 필요할 것으로 생각된다. 